\title{
VIRTUALISASI KATALOG SENAYAN LIBRARY MANAGEMENT SYSTEM (SLiMS) BERBASIS 3D
}

\author{
Sopingi ${ }^{1}$, Mei Purweni ${ }^{2}$ \\ ${ }^{1}$ Sistem Informasi, ${ }^{2}$ Teknik Komputer \\ STMIK Duta Bangsa Surakarta \\ Email : sopingi@stmikdb.ac.id ${ }^{1}$, mei_purweni@stmikdb.ac.id ${ }^{2}$
}

\begin{abstract}
ABSTRAK
Kemajuan information and communication technology telah merubah paradigma pola pembelajaran, pola interaksi dan pola pengelolaan sistem di perguruan tinggi. Saat ini di lingkungan perguruan tinggi, perpustakaan digital diperlukan untuk mendukung pelaksanaan pendidikan dan pengajaran, penelitian serta pengabdian dan pelayanan pada masyarakat. Aplikasi open source perpustakaan digital yang ada di Indonesia adalah Senayan Library Management System yang menyediakan fitur Online Public Access Catalog (OPAC). Permasalahan yang terjadi adalah OPAC dari SLiMS tidak ada fitur yang menunjukan lokasi dari buku.

Tujuan penelitian ini adalah menghasilkan aplikasi virtualisasi katalog SLiMS untuk penataan buku di rak dan pencarian buku dalam bentuk 3D serta mengetahui keakuratan dan performance.

Metode dilakukan diawali membuat struktur vertex dari buku dan rak dengan menggunakan data polyhedron dari objek kubus. Data polyhedron dapat dibaca dengan aplikasi Blender 3D, kemudian penulis analisis untuk mendapatkan rumus pembentuk polyhedron serta mendapatkan urutan index dari vertex. Data masukkan yang digunakan untuk membentuk polyhedron buku adalah panjang, lebar dan tebal buku, sedangkan untuk polyhedron rak adalah panjang, lebar, tinggi dan tebal papan. Data masukkan disimpan di basis data agar dapat diakses dan dikonversi menjadi 3D dengan pemrograman web.

Hasil penelitian berupa aplikasi prototype yang dapat membuat almari dan rak dalam bentuk 3D serta membuat buku dalam bentuk 3D berdasarkan data dari basis data SLiMS. Berdasarkan hasil pengujian protoype, aplikasi dapat berjalan sesuai kebutuhan dengan hasil sangat setuju $65 \%$, setuju $25 \%$ dan cukup setuju $10 \%$. Buku yang dapat ditampilkan dalam bentuk 3D kurang dari 250 buku.
\end{abstract}

Kata Kunci: SLiMS, OPAC, Polyhedron, 3 dimensi, Prototype

\begin{abstract}
The progress of information and communication technology has changed the paradigm of learning patterns, patterns of interaction and pattern of system management in universities. Currently in college environments, digital libraries are needed to support the implementation of education and teaching, research and community service. Open source digital library application in Indonesia is Senayan Library Management System that provides features Online Public Access Catalog
\end{abstract}


(OPAC). The problem is OPAC from SLiMS there is no feature showing the location of the book.

The purpose of this research is to generate the SLiMS catalog virtualization application for rack book arrangement and $3 D$ book search as well as to know the accuracy and performance.

The method is done begins to create the vertex structure of the book and rack by using polyhedron data from the object of the cube. The polyhedron data can be read with the $3 D$ Blender application, then the analytical writer to get the polyhedron formulas and get the index order from the vertex. The insert data used to form the book polyhedron is the length, width and thickness of the book, while for the polyhedron rack is the length, width, height and thickness of the board. The insert data is stored in the database in order to be accessible and converted into $3 D$ with web programming.

The result of the research is prototype application that can make cabinet and shelf in 3D and make book in 3D form based on data from SLiMS database. Based on protoype test result, application can run as needed with result very agree 65\%, agree $25 \%$ and enough agree $10 \%$. Books that can be displayed in $3 D$ without less than 250 books

Keywords: SLiMS, OPAC, Polyhedron, 3 dimensions, Prototype

\section{PENDAHULUAN}

Kemajuan Information And Communication Technology (ICT) telah merubah paradigma pola pembelajaran, pola interaksi dan pola pengelolaan sistem di perguruan tinggi. Sesuai pernyataan PT. Telkom dalam talkshow Telkom Smart Campus Award (TeSCA) pada tahun 2013 bahwa dengan menerapkan ICT dapat meningkatkan daya saing perguruan tinggi menuju World Class University. Untuk mewujudkan kampus berbasis ICT, perlu dibangun infrastruktur digital di dalam kampus yang dapat dimanfaatkan dengan berbagai jenis layanan baik untuk keperluan internal kampus maupun eksternal sehingga memberikan nilai tambah terhadap keberadaan kampus dalam masyarakat.

Saat ini di lingkungan perguruan tinggi, perpustakaan digital diperlukan untuk mendukung pelaksanaan pendidikan dan pengajaran, penelitian serta pengabdian dan pelayanan pada masyarakat (Rodliyah, 2012). Perpustakaan digital menawarkan berbagai macam cara penelusuran dengan menyediakan database secara elektronik sehingga memudahkan kepada pengguna untuk akses informasi, 
istilah ini sering disebut sebagai katalog. Katalog online atau Open Public Access Catalogue (OPAC) yang dirancang dengan baik merupakan kunci keberhasilan penerapan automasi perpustakaan (Arif, 2003).

Aplikasi open source perpustakaan digital yang ada di Indonesia adalah Senayan Library Management System (SLiMS). SLiMS menyediakan fitur Online Public Access Catalog (OPAC) yang sudah memiliki standart berdasarkan schema.org dan Dublin Core. Permasalahan yang terjadi adalah OPAC dari SLiMS tidak ada fitur yang menunjukan lokasi dari buku atau bahan pustaka berada, sehingga mengakibatkan kesulitan bagi pengunjung untuk mencari lokasi buku atau bahan pustaka berada.

Berdasarkan latar belakang diatas penulis melakukan penelitian pengembangan virtualisasi katalog Senayan Library Management System (SLiMS) berbasis 3D yang mempunyai fitur menampilkan buku dan rak dalam bentuk 3D serta mampu melakukan tracking pencarian buku. Mengingat pentingnya keakuratan dan performance terhadap virtualisasi katalog yang dikembangkan, maka juga dikaji teknik penentuan lokasi dan pengukuran buku agar dapat ditranformasikan ke dalam objek 3D serta pengujian performance-nya. Rumusan masalah yang akan dibahas sebagai berikut: (1) Bagaimana menganalisa, merancang dan membangun virtualisasi katalog Senayan Library Management System (SLiMS) berbasis 3D yang dapat memberikan informasi lokasi dan meta data dari bahan pustaka?, (2) Bagaimana mentransformasikan data panjang, lebar, tebal dan lokasi dari buku menjadi bentuk objek 3D?, (3). Bagaimana menguji keakuratan dan performance aplikasi virtualisasi katalog Senayan Library Management System (SLiMS) berbasis 3D?. Batasan penelitian yang dilakukan adalah mengembangkan basisdata katalog Senayan Library Management System (SLiMS) agar dapat ditampilkan dalam bentuk 3D, membuat buku dan rak bentuk 3D, membuat fungsi untuk transformasi panjang, lebar dan tebal buku kedalam bentuk polyhedron, membuat fungsi untuk menentukan lokasi buku di dalam rak, mengembangkan pencarian buku dengan animasi tracking untuk menunjukan 
lokasi bahan pustaka yang dicari, melakukan pengujian keakuratan dan performance virtualisasi katalog.

Sebagai pendukung dalam penelitian yang dilakukan berikut tinjauan pustaka terdahulu: (1) Penelitian "Interactive Application Development Policy Object 3D Virtual Tour History Pacitan District based Multimedia" oleh Muga Linggar Famukhit (2013) menghasilkan media informasi aplikasi interaktif sejarah tour Pacitan 3D virtual dalam bentuk aplikasi CD interaktif dan bersifat statis. Berbeda dengan penelitian yang penulis lakukan yaitu fokus dengan merubah data geometri menjadi bentuk 3D yang bersifat dinamis. (2) Qurrotul Ainia (2012) dalam penelitiannya “3D Catalog Of Rare Medicinal Plants". Melakukan penelitian media informasi tanaman obat langka meliputi bentuk tanaman, khasiat, pabrik pengolahan dan budidaya. Katalog digital yang dibuat berupa 20 spesies tanaman objek 3D yang didesain menggunakan aplikasi 3D. Sedangkan dalam penelitian penulis dapat menampilkan object sesuai jumlah data yang ada di database dengan menggunakan data geometri. (3) Penelitian sebelumnya yang dilakukan oleh Sulastri (2007) dengan judul "Transformasi Bangun Ruang Tiga Dimensi menggunakan Visual Basic 6.0" menghasilkan algoritma pemrograman yang digunakan untuk mentranformasi object 3D. Tujuannya adalah untuk membuat software yang dapat menunjukkan bahwa suatu benda tiga dimensi dapat ditransformasikan berdasarkan fungsi-fungsi geometri. Penelitian ini sejalan dengan yang penulis lakukan, tetapi penulis menkonverikan data menjadi data polyhedron yang dapat digunakan untuk menampikan objek 3D, posisi dan gambar texture.

Penelitian ini menghasilkan aplikasi virtualisasi katalog SLiMS untuk penataan buku di rak dan pencarian buku dalam bentuk 3D serta mengetahui keakuratan dan performance dari aplikasi yang telah dibuat. 


\section{METODE PENELITIAN}

Tahapan dalam penelitian ini penulis mengadopsi metode pengembangan aplikasi multimedia yaitu Interactive Multimedia System Design and Development (IMSDD) kemudian disesuaikan dengan kebutuhan penelitian. Berikut gambar 1 merupakan tahapan penelitian yang dilakukan

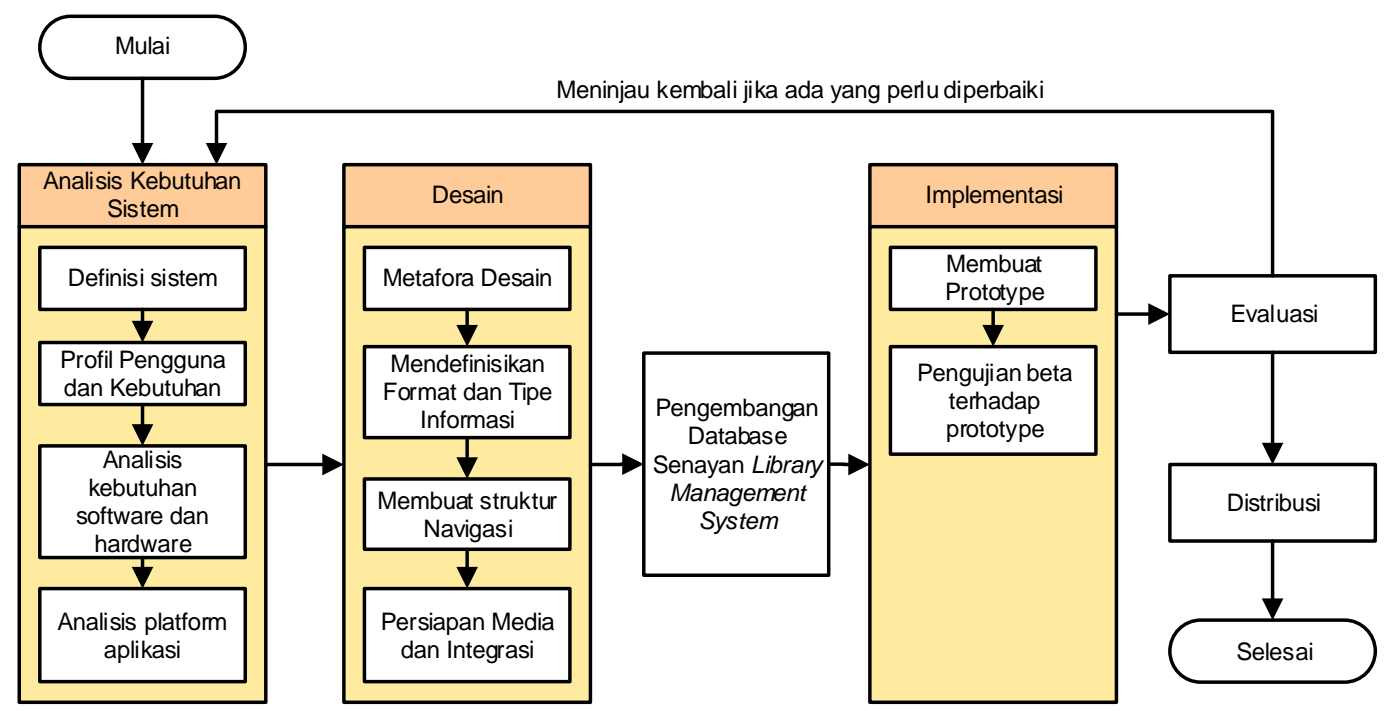

Gambar 1. Tahapan Penelitian

Berikut penjelasan dari masing-masing tahapan penelitian diatas:

1. Definisi Sistem, menentukan tujuan dan sasaran yang akan dicapai dari aplikasi virtualisasi katalog yang dibuat.

2. Profil pengguna dan kebutuhan, memastikan dan menganalisa siapa sajakah pengguna dari aplikasi virtualisasi katalog yang dibuat beserta kebutuhan spesifik yang dibutuhkan oleh masing-masing pengguna.

3. Analisis kebutuhan software dan hardware, menganalisa dan mengevaluasi hardware dan software yang dibutuhkan baik pada saat perancangan, pembuatan, implementasi sampai pengujian

4. Analisis platform aplikasi, menganalisa kebutuhan agar aplikasi dapat berjalan di berbagai platform

5. Metafora desain, Objek yang akan digunakan sebagai metafora desain adalah rak, buku dan Senayan Library Management System yang ada di STMIK Duta Bangsa Surakarta. 
6. Mendefinisikan tipe dan format informasi, untuk menggambarkan buku dalam bentuk 3D digunakan format berupa matrik dari data geometri. Sedangkan informasi yang tertulis berupa teks dan gambar yang diambil dari database Senayan Library Management System.

7. Membuat struktur navigasi, navigasi dibuat berdasarkan metafora desain, sehingga navigasi akan lebih terstruktur dan mudah dipahami, karena sesuai dengan keadaanya sebenarnya.

8. Persiapan media dan integrasi, media yang digunakan adalah data yang sudah ada di Senayan Library Management System. Pada tahap ini dibuat juga fungsi untuk transformasi data panjang, lebar dan tebal dari buku ke dalam bentuk data polyhedron, kemudian ditentukan lokasi di dalam rak buku.

9. Pengembangan Database Senayan Library Management System, menambahkan field yang digunakan untuk menyimpan data panjang, lebar dan tebal dari buku.

10. Membuat prototype, menggunakan aplikasi Blender 3D dengan menggunakan library blend4web. Sedangkan untuk integrasi dengan SliMS digunakan web service.

11. Pengujian terhadap prototype, melakukan pengujian apakah aplikasi yang dibuat sudah sesuai tujuan dan sasaran yang telah dirumuskan dan juga dilakukan pengujian terhadap keakuratan dan performance aplikasi ketika dijalankan.

\section{HASIL DAN PEMBAHASAN}

\section{Metafora Desain}

Objek 3D terbentuk karena ada kumpulan titik-titik yang disebut vertex yang saling terhubung sehingga membentuk polyhedron. Bentuk dasar buku merupakan bentuk kubus, untuk mendapatkan titik-titik vertex penulis menggunakan ukuran buku berupa panjang, lebar dan tebal buku. Data panjang dan lebar buku sudah tertera di halaman identitas buku, data tebal buku diperoleh dengan menggunakan rumus jumlah halaman dikalikan dengan 0.1 
mm sedangkan objek 3D diperkecil adalah $2 \%$ dari ukuran sebenarnya atau skala $2: 100 \mathrm{~cm}$.

Struktur titik atau vertex dari buku dan rak dapat diambil dengan meniru data polyhedron dari objek 3D kubus. Data polyhedron kubus dapat dibaca menggunakan aplikasi Blender 3D kemudian penulis analisis untuk mendapatkan rumus pembentuk polyhedron serta mendapatkan urutan index dari titik-titik tersebut. Berikut gambar 2 merupakan hasil analisis data polyhedron kubus yang dibuat di aplikasi Blender 3D yang kemudian menjadi dasar untuk membentuk buku 3D.
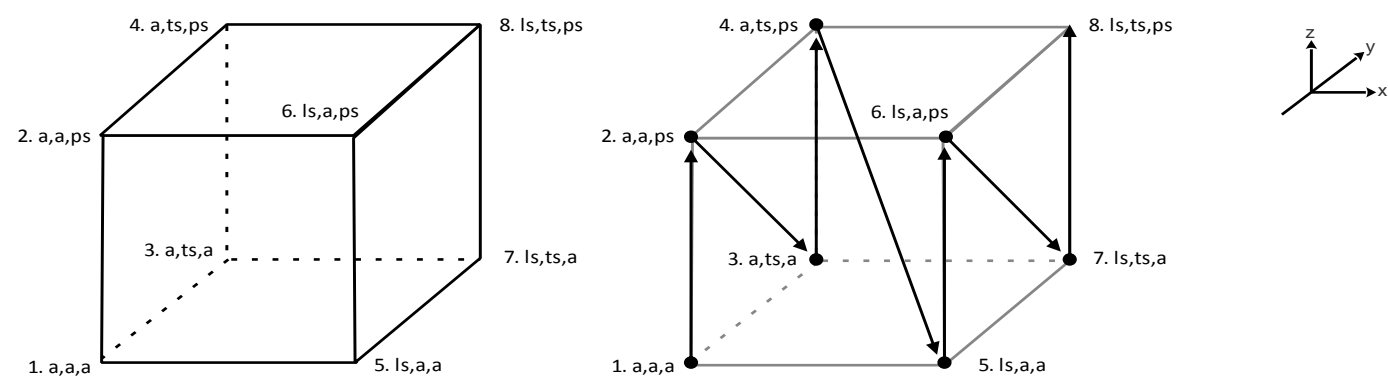

Gambar 2. Metafora Desain Polyhedron Buku

Keterangan Gambar 2 :

a = Titik awal,

ps = Panjang buku,

ls = Lebar buku

ts $=$ Tebal buku

adapun data polyhedron yang berupa matrik dengan index titik-titik dari gambar 2 adalah: a, a, a, a, a, ps, a, ts, a, a, ts, ps, ls, a, a, ls, a, ps, ls, ts, a, ls, ts, ps.

Sedangkan analisis data polyhedron pembentuk rak 3D menggunakan data panjang, lebar, tinggi dan tebal papan. Sama seperti buku, rak dibuat dengan meniru data polyhedron dari objek 3D kubus yang dipotong dengan objek 3D kubus yang lebih kecil. Adapun hasil analisis data polyhedron pembentuk rak 3D seperti pada gambar 3 berikut ini. 


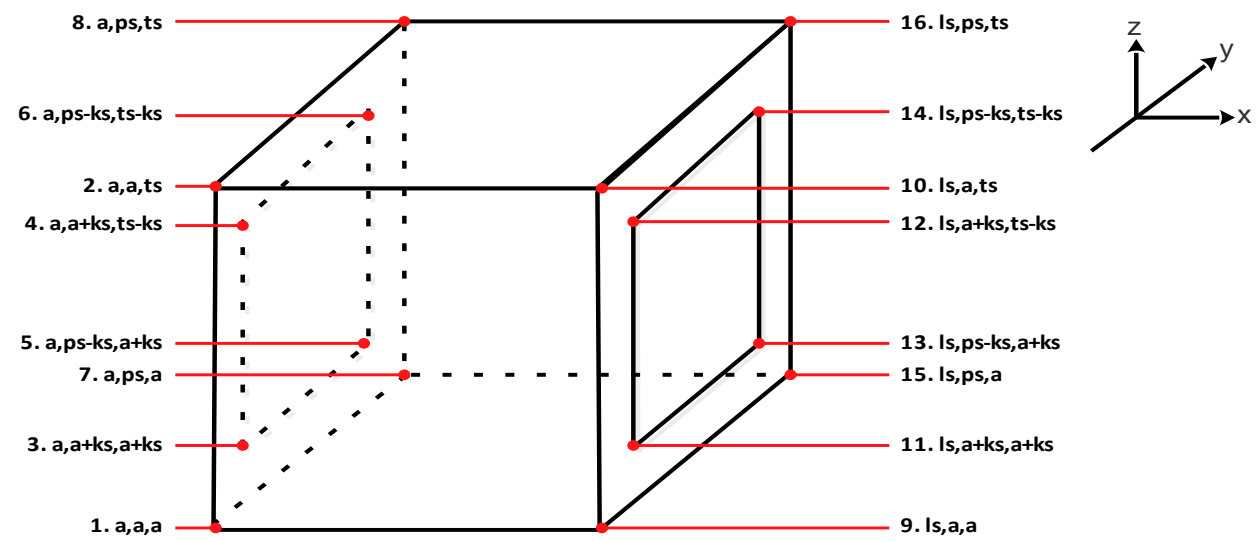

Gambar 3. Metafora Desain Polyhedron Rak

Keterangan Gambar 3 :

a = Titik awal,

ps $=$ Panjang rak

ls = Lebar rak

ts $=$ Tinggi rak

$\mathrm{ks}=$ Tebal papan

adapun data polyhedron yang berupa matrik dengan index titik-titik dari gambar 3 adalah: a, a, a, a, a, ts, a, a+ks, a+ks, a, a+ ks, ts-ks, a, ps-ks, a+ks, a, ps-ks, tsks, a, ps, a, a, ps, ts, ls, a, a, ls, a, ts, ls, a+ks, a+ks, ls, a+ks, ts-ks, ls, ps-ks, a+ks, ls, ps-ks, ts-ks, ls, ps, a, ls, ps, ts.

\section{Pengembangan Basis Data}

Ada 2 (dua) pengembangan basis data yaitu pengembangan tabel biblio_custom dari basis data SLiMS dan penambahan tabel baru yaitu almari dan rak. Struktur pengembangan basis data dapat dilihat pada tabel 1 untuk pengembangan tabel almari, tabel 2 untuk pengembangan tabel rak dan tabel 3 . Untuk pengembangan tabel biblio_custom. Tabel biblio_custum digunakan untuk menyimpan data panjang, lebar dan tebal buku. 
Tabel 1. Struktur Tabel Almari

\begin{tabular}{|c|c|c|}
\hline Nama Field & Tipe / Panjang & Keterangan \\
\hline almari_id & $\operatorname{int}(8)$ & Primary Key \\
\hline almari_nama & $\operatorname{varchar}(255)$ & \\
\hline geometry & text & $\begin{array}{l}\text { Format data json: } \\
\{" \mathrm{p} ": 100, " 1 ": 50, " \mathrm{x} ": 90, " \mathrm{y} ": 10, " \mathrm{r} ": 90\} \\
\mathrm{p}: \text { panjang almari } \\
1: \text { lebar almari } \\
\mathrm{x}: \text { posisi koordinat } X \\
\mathrm{y}: \text { posisi koordinat } \mathrm{Y} \\
\mathrm{r}: \text { rotasi almari }\end{array}$ \\
\hline created_at & datetime & \\
\hline updated_at & datetime & \\
\hline
\end{tabular}

Tabel 2. Struktur Tabel Rak

\begin{tabular}{|c|c|c|}
\hline Nama Field & Tipe / Panjang & Keterangan \\
\hline rak_id & $\operatorname{int}(8)$ & Primary Key \\
\hline almari_id & $\operatorname{int}(8)$ & Foreign Key \\
\hline urut & $\operatorname{int}(2)$ & Urutan rak dari bawah ke atas \\
\hline geometry & text & $\begin{array}{l}\text { Format data json: } \\
\{\text { "p":100,"l":50,"t":50,"k":0.5\} } \\
\text { p : panjang rak } \\
1 \text { : lebar rak } \\
\text { t: tinggi rak } \\
\mathrm{k}: \text { tebal papan }\end{array}$ \\
\hline created_at & datetime & \\
\hline updated_at & datetime & \\
\hline
\end{tabular}

Tabel 3. Struktur Tabel Biblio Custom

\begin{tabular}{|l|l|l|}
\hline Nama Field & Tipe / Panjang & \multicolumn{1}{|c|}{ Keterangan } \\
\hline biblio_id & int (11) & $\begin{array}{l}\text { Primary Key } \\
\text { Berlasi One to One dengan tabel biblio }\end{array}$ \\
\hline panjang & int (2) & Panjang Buku \\
\hline lebar & int (2) & Lebar Buku \\
\hline tebal & int (4) & Jumlah Halaman Buku \\
\hline
\end{tabular}




\section{Membuat Prototype}

Aplikasi yang dibuat masih berupa prototype yang digunakan untuk membuat almari dan rak dalam bentuk 3D dan membuat buku dalam bentuk 3D menggunakan data sampel.

a. Penambahan kode untuk field custom pada bibliografi di SliMS

Penambahan kode untuk field custom dilakukan pada file admin \moduleslbibliographylcustom_fields.inc.php sebagai berikut:

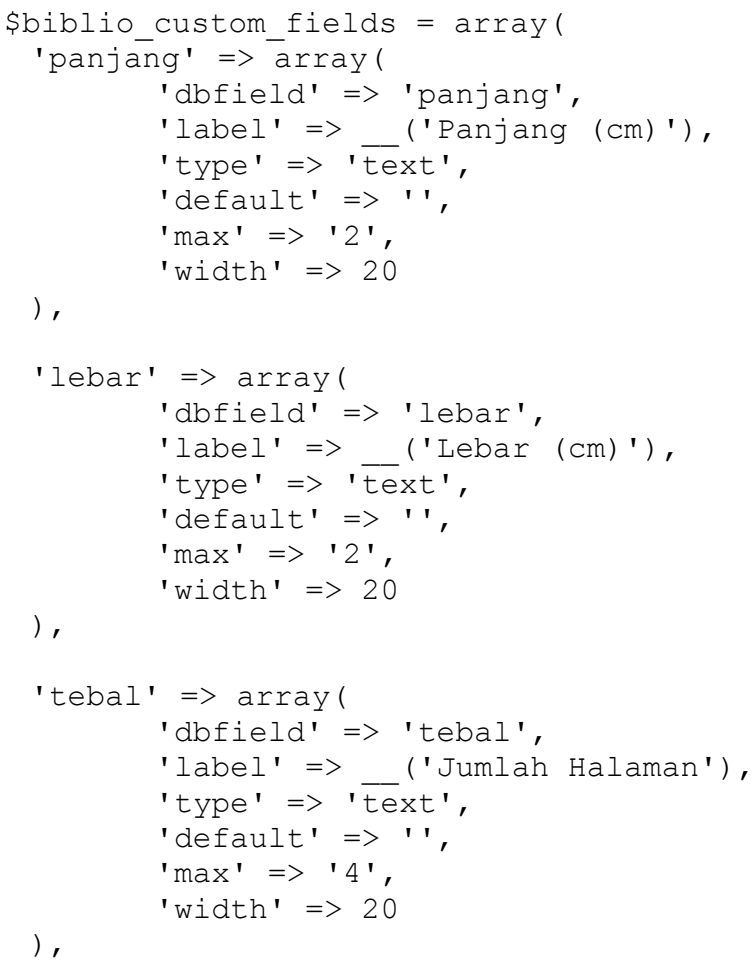

b. Aplikasi Pembuat Almari dalam bentuk 3D

Almari dibuat dengan menggunakan ukuran panjang dan lebar, sedangkan tinggi almari ditentukan oleh jumlah dan tinggi rak. Tampilan aplikasi pembuat almari dapat di lihat pada gambar 4 dan 5 . 


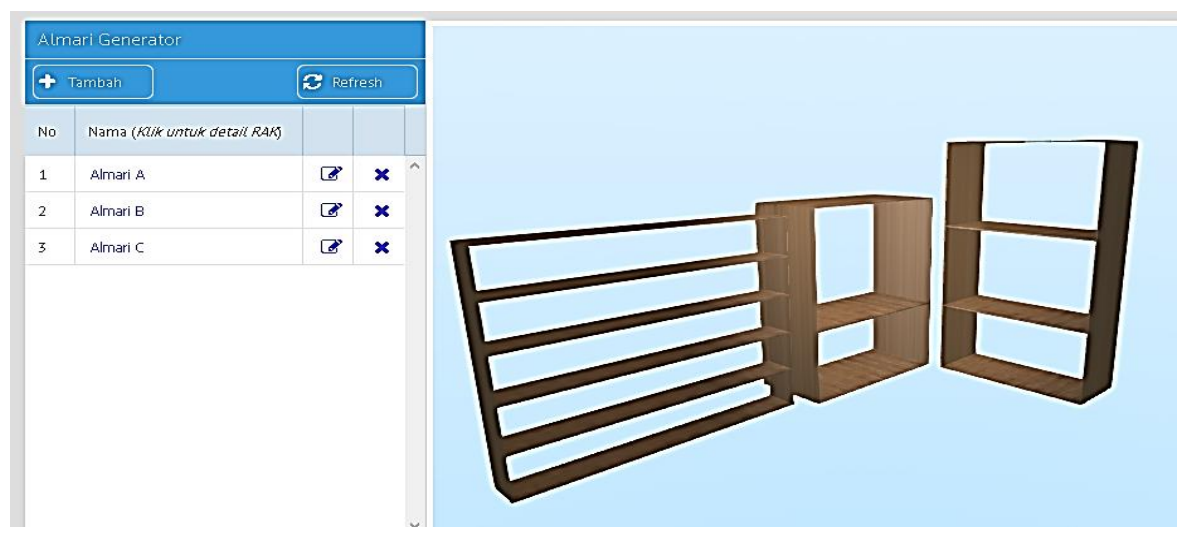

Gambar 4. Aplikasi Pembuat Almari dalam Bentuk 3D

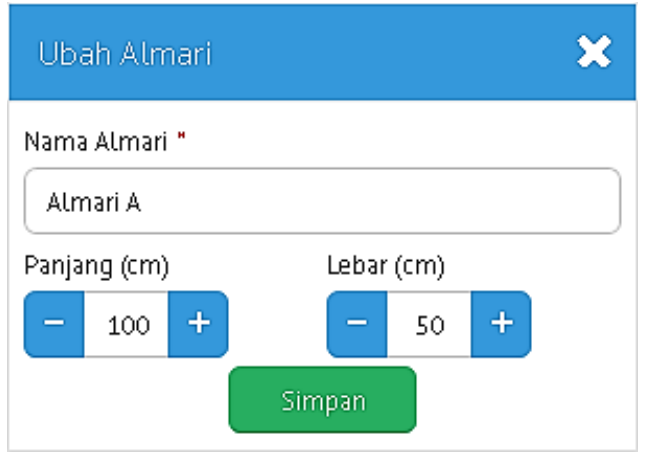

Gambar 5. Form Input Data Almari

c. Aplikasi Pembuat Rak dalam bentuk 3D

Rak dibuat dengan menggunakan ukuran tinggi dan tebal papan. Tampilan aplikasi pembuat rak dapat di lihat pada gambar 6 dan 7 .

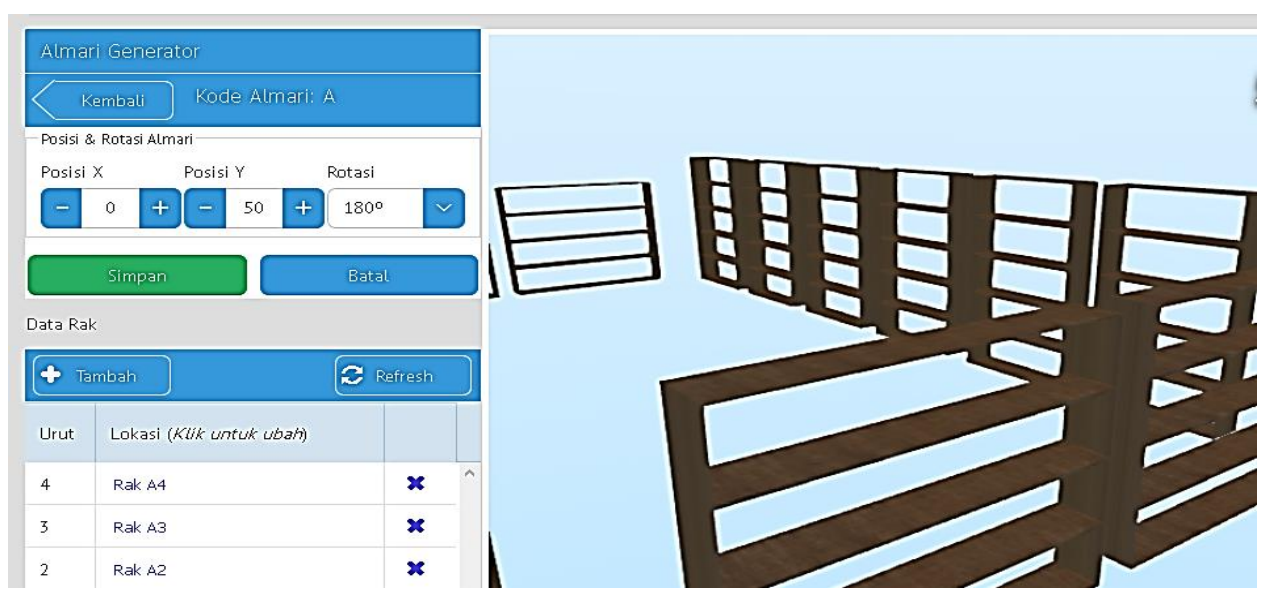

Gambar 6. Aplikasi Pembuat Rak dalam Bentuk 3D 


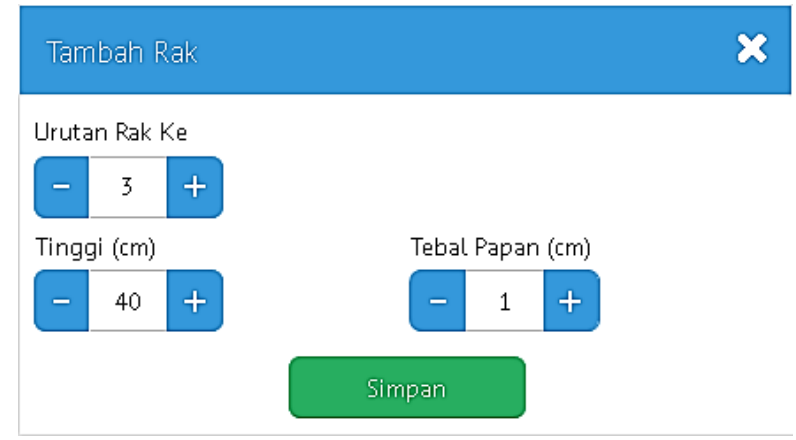

Gambar 7. Form Input Data Rak

d. Aplikasi Katalog Buku dalam bentuk 3D

Buku tampil berdasarkan urutan call number dan urutan pada rak. Jika buku dipilih maka akan menampilkan meta data dari buku seperti pada gambar 8 .

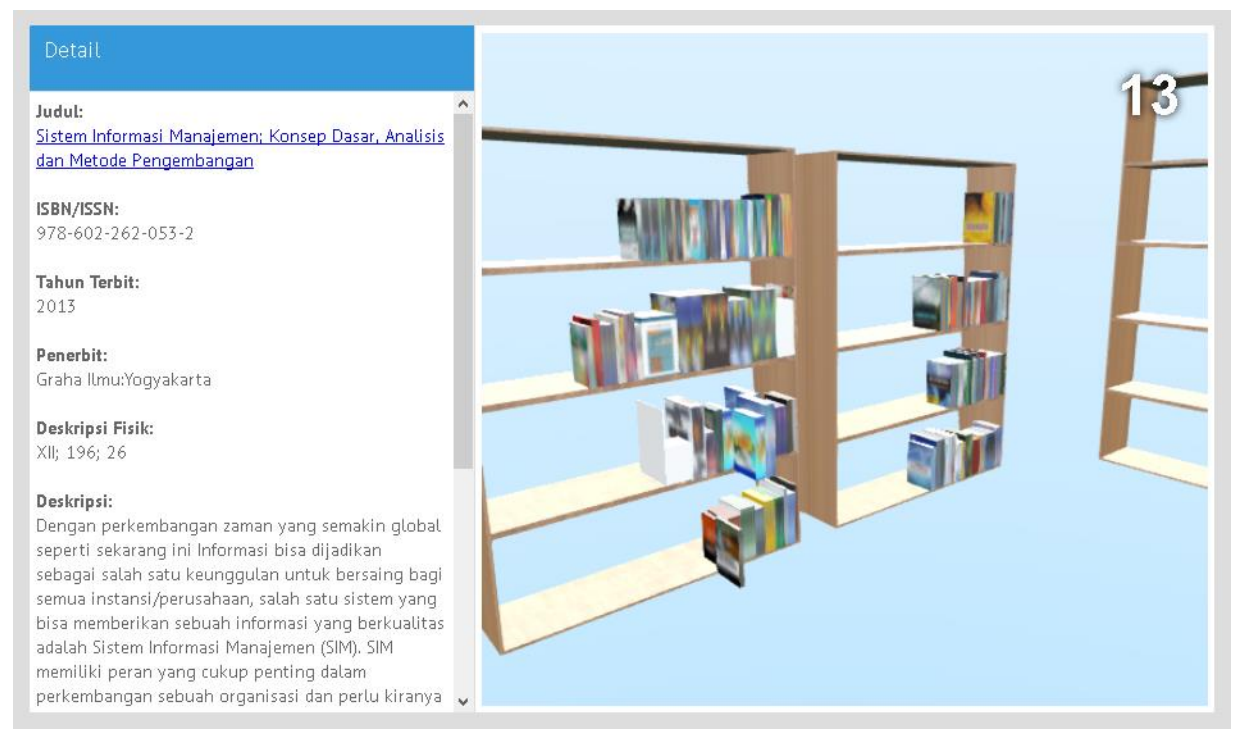

Gambar 8. Katalog Buku 3D

\section{Pengujian Prototype}

Pengujian dilakukan dengan menggunakan pengujian beta dengan melibatkan 5 perguruan tinggi untuk memberikan berbagai kondisi infrastuktur perpustakaan dan membantu pendataan buku. Pengujian dengan menggunakan skenario uji terhadap aplikasi menyesuaikan analisis kebutuhan. Hasil pengujian yang telah dilakukan disajikan pada tabel 4 berikut ini. 
Tabel 4. Hasil Pengujian Beta Virtualisasi Katalog Berbasis 3D

\begin{tabular}{|c|c|c|c|c|}
\hline No & Pernyataan & Pilihan & Responden & Prosentase \\
\hline \multirow[t]{5}{*}{1} & \multirow{5}{*}{$\begin{array}{l}\text { Aplikasi Prototype } \\
\text { katalog berbasis 3D } \\
\text { dapat diakses dengan } \\
\text { mudah dan cepat }\end{array}$} & Sangat Setuju & 3 & $60 \%$ \\
\hline & & Setuju & 2 & $40 \%$ \\
\hline & & Cukup Setuju & 0 & $0 \%$ \\
\hline & & Kurang Setuju & 0 & $0 \%$ \\
\hline & & Tidak Setuju & 0 & $0 \%$ \\
\hline \multicolumn{3}{|r|}{ Jumlah } & 5 & $100 \%$ \\
\hline \multirow[t]{5}{*}{2} & \multirow{5}{*}{$\begin{array}{l}\text { Aplikasi Prototype } \\
\text { dapat membuat } \\
\text { Almari dan Rak } \\
\text { tampil 3D seperti } \\
\text { keadaan sebenarnya }\end{array}$} & Sangat Setuju & 3 & $60 \%$ \\
\hline & & Setuju & 1 & $20 \%$ \\
\hline & & Cukup Setuju & 1 & $20 \%$ \\
\hline & & Kurang Setuju & 0 & $0 \%$ \\
\hline & & Tidak Setuju & 0 & $0 \%$ \\
\hline \multicolumn{3}{|r|}{ Jumlah } & 5 & $100 \%$ \\
\hline \multirow[t]{5}{*}{3} & \multirow{5}{*}{$\begin{array}{l}\text { Aplikasi Prototype } \\
\text { dapat menampilkan } \\
\text { buku ke dalam } \\
\text { bentuk 3D }\end{array}$} & Sangat Setuju & 5 & $100 \%$ \\
\hline & & Setuju & 0 & $0 \%$ \\
\hline & & Cukup Setuju & 0 & $0 \%$ \\
\hline & & Kurang Setuju & 0 & $0 \%$ \\
\hline & & Tidak Setuju & 0 & $0 \%$ \\
\hline \multicolumn{3}{|r|}{ Jumlah } & 5 & $100 \%$ \\
\hline \multirow[t]{5}{*}{4} & \multirow{5}{*}{$\begin{array}{l}\text { Buku 3D tampil } \\
\text { berdasarkan urutan } \\
\text { seperti keadaan } \\
\text { sebenarnya }\end{array}$} & Sangat Setuju & 2 & $40 \%$ \\
\hline & & Setuju & 2 & $40 \%$ \\
\hline & & Cukup Setuju & 1 & $20 \%$ \\
\hline & & Kurang Setuju & 0 & $0 \%$ \\
\hline & & Tidak Setuju & 0 & $0 \%$ \\
\hline & & Jumlah & 5 & $100 \%$ \\
\hline
\end{tabular}

Dari hasil pengujian pada tabel 4 dapat dilakukan perhitungan dengan menggunakan rumus:

$$
\frac{\text { Jumlah masing }- \text { masing pilihan }}{\text { Jumlah Responden } \times \text { Jumlah Pernyataan }} \times 100 \%
$$

$\begin{array}{lll}\text { Sangat Setuju } & : 13 / 20 * 100 \% & =65 \% \\ \text { Setuju } & : 5 / 20 * 100 \% & =25 \% \\ \text { Cukup Setuju } & : 2 / 20 * 100 \% & =10 \% \\ \text { Kurang Setuju } & : 0 / 20 * 100 \% & =0 \% \\ \text { Tidak Setuju } & : 0 / 20 * 100 \% & =0 \%\end{array}$


Sedangkan pengujian performa Virtualisasi Katalog Berbasis 3D yang berupa kemampuan menampilkan bentuk 3D buku dan waktu yang dibutuhkan dapat dilihat pada tabel 5 berikut ini.

Tabel 5. Hasil Pengujian Performa Virtualisasi Katalog Berbasis 3D

\begin{tabular}{|c|c|c|c|c|c|}
\hline \multirow{2}{*}{ Responden } & \multicolumn{5}{|c|}{ Waktu (detik) } \\
\cline { 2 - 6 } & 50 Buku & 100 Buku & 150 Buku & 200 Buku & 250 Buku \\
\hline 1 & 5 & 8 & 28 & 142 & error \\
\hline 2 & 7 & 14 & 49 & 159 & error \\
\hline 3 & 11 & 18 & 40 & 135 & error \\
\hline 4 & 6 & 10 & 34 & 144 & error \\
\hline 5 & 13 & 21 & 51 & 163 & error \\
\hline Rata-rata & 8.4 & 14.2 & 40.4 & 148.6 & - \\
\hline
\end{tabular}

Dari hasil perhitungan tabel 4 dapat disimpulkan bahwa aplikasi yang telah dibuat dapat berjalan sesuai analisis kebutuhan, tetapi berdasarkan tabel 5 diketahui bahwa virtualisasi katalog 3D tidak dapat menampilkan 250 buku atau lebih dikarenakan browser tidak mampu menyelesaikan proses serta mengakibatkan komputer down, sehingga masih diperlukan metode lain agar dapat menampilkan seluruh buku yang ada di database SLiMS.

\section{KESIMPULAN DAN SARAN}

Berdasarlam hasil pembahasan dan pengujian dapat ditarik kesimpulan sebagai berikut:

1. Aplikasi dapat melakukan pembuatan almari dan rak dalam bentuk $3 \mathrm{D}$

2. Buku 3D dapat dibuat menggunakan data panjang, lebar dan tebal yang dikonversi menjadi data polyhedron terlebih dahulu

3. Berdasarkan hasil pengujian protoype aplikasi dapat berjalan sesuai kebutuhan dengan hasil sangat setuju $65 \%$, setuju $25 \%$ dan cukup setuju $10 \%$

4. Buku yang dapat ditampilkan dalam bentuk 3D kurang dari 250 buku.

Adapun saran untuk peneliti berikutnya adalah sebegai berikut: 
1. Peningkatan performa akses dengan menggunakan data yang besar sehingga dapat menampilkan seluruh buku dalam bentuk 3D.

2. Pengembangan aplikasi katalog 3D berbasis Android agar lebih fleksibel

\section{UCAPAN TERIMA KASIH}

Penulis mengucapkan terima kasih kepada Direktorat Riset dan Pengabdian Masyarakat, Direktorat Jenderal Penguatan Riset dan Pengembangan, Kementerian Riset, Teknologi, dan Pendidikan Tinggi Republik Indonesia yang telah memberi dukungan terhadap penelitian ini sehingga dapat terlaksana pada tahun 2018

\section{DAFTAR PUSTAKA}

Ainia, Qurrotul. dkk. 2012. 3D Catalog Of Rare Medicinal Plants. International Conference on Advances Science and Contemporary Engineering (pp 188194). Jakarta: Bina Nusantara University.

Arif, I. 2003. Konsep dan perencanaan dalam automasi perpustakaan. Seminar Sehari Membangun Jaringan Perpustakaan Digital dan Otomasi Perpustakaan menuju Masyarakat Berbasis Pengetahuan. Malang: Universitas Muhammadiyah Malang.

Famukhit, Muga Linggar, dkk. 2013. Interactive Application Development Policy Object 3D Virtual Tour History Pacitan District based Multimedia. International Journal of Advanced Computer Science and Applications (IJACSA) Vol. 4 No.3, 15-19.

Rodliyah, Ummi. 2012. Perpustakaan Digital, dan Prospeknya Menuju Resource Sharing. Visi Pustaka Vol. 14 No. 1, 39-47.

Sulastri. 2007. Transformasi Bangun Ruang Tiga Dimensi menggunakan Visual Basic 6.0. Jurnal Teknologi Informasi DINAMIK Volume XII, No.1, 88-100.

TeSCA. (2014). Perkuat Langkah Menuju World Class University. website: www.tescaindonesia.org/content/news/strengthening-step-towards-worldclass-university/read 